\title{
A Scanning Electron Microscope Study of the Effect of an Enterotoxin from Clostridium perfringens 8-6 on Mice of Different Ages
}

\author{
By JAMES A. LINDSAY*† AND JANE D. DENNISON \\ CSIRO Division of Food Research, PO Box 52, North Ryde, NSW 2113, Australia
}

(Received 10 February 1986; revised 12 May 1986)

Intestinal damage to mice caused by an enterotoxin from a coatless spore mutant of Clostridium perfringens type A (8-6) was examined by scanning electron microscopy. Two distinct types of damage were observed, both of which could be correlated with animal age. Damage appeared to occur in a specific sequence similar to that found in previous studies in rabbits. We conclude that the type of ileal tissue damage reflects the mode of toxin incorporation from the gut, which is a function of animal age.

\section{INTRODUCTION}

Recently we isolated and characterized an enterotoxin from a coatless spore mutant of Clostridium perfringens type A (8-6) (Lindsay et al., 1985) which bore no antigenic relationship to the enterotoxin previously isolated from normal coated $C$. perfringens type A spores (McDonel, 1980). Examination of the effect of this 8-6 enterotoxin on rabbit ileal tissue revealed that two distinct types of damage could occur (Lindsay \& Dennison, 1986). Further, an apparent relationship between the type of damage and the age of the animal was noted, younger animals appearing to have greater damage to the lamina propria than to the villus enterocytes. This observation prompted us to examine first, the effect of the 8-6 enterotoxin on the ileum of mice of different ages to determine if a relationship existed between type of damage and age and, second, whether enterotoxin damage occurred in a specific sequence. We chose to examine these problems only by scanning electron microscopy (SEM) as SEM data were available for comparison (Lindsay \& Dennison, 1986). Further, this method permitted examination of a large number of samples corresponding to a representative area of the gut surface, which would have been difficult using transmission electron microscopic techniques. The mouse system was chosen for several reasons: first, familiarity, since in a previous study (Lindsay et al., 1985) we had used the mouse system; second, ease in obtaining large quantities of pure strain animals; and third, the development of intestinal function in the mouse has been extensively studied and is similar to development of the human gut (Henning \& Kretchmer, 1973; Johnson, 1981). The latter point was of concern to us as we are interested in the role(s) of bacterial toxins in diseases previously characterized as 'aetiologically unknown' and in infant botulism (Arnon et al., 1978; Arnon, 1980).

\section{METHODS}

Enterotoxin. Enterotoxin was prepared and the activity in erythemal units was determined as described previously (Lindsay et al., 1985).

Animal preparation. Swiss White (Quackenbush) mice 6, 9 and $12 \mathrm{~d}$ old were injected with $100 \mu$ enterotoxin ( $1 \mathrm{ng}$ ) in $0.85 \%(\mathrm{w} / \mathrm{v})$ saline, $\mathrm{pH} 6.7$, or the equivalent volume of saline alone, directly into the stomach, using a $1 \mathrm{ml}$ syringe with a 27 gauge, $13 \mathrm{~mm}$ hypodermic needle. Older mice (15 and $18 \mathrm{~d})$ were fed $100 \mu$ lenterotoxin or

† Present address: Department of Food Science and Human Nutrition, University of Florida, Gainesville, FL 32611, USA.

Abbreviation: SEM, scanning electron microscopy. 
saline orally since the stomach is difficult to locate at this age. Nine-day-old mice were used as a control to check the effectiveness of oral administration (see Discussion). After $10 \mathrm{~h}$ the mice were killed by decapitation and the small intestine was dissected out and washed very gently in ice-cold saline. Samples were also taken from untreated mice to ensure that injection of saline alone caused no morphological damage to the tissue. All experiments were done using at least three mice at each age for each treatment. Samples for SEM were prepared and examined as previously described (Lindsay \& Dennison, 1986).

\section{RESULTS}

On gross examination, the ileal tissue of animals treated with enterotoxin showed some slight engorgement of the blood vessels surrounding the tissue, while control animals showed no physiological abnormalities. During lengthwise sectioning and washing, it was noticed that all the enterotoxin-treated tissue was extremely fragile, great care having to be taken in handling it.

SEM examination of saline or untreated mouse ileal tissue (Fig. $1 a$ ) showed villi of normal size, shape and texture. Figs $1(b)$ and $1(c)$ show the effect of enterotoxin on 6- and 9-d-old mice. The villi bear little resemblance to the control tissue and show one form of tissue damage only, that to the lamina propria. Figs $1(d)$ and $1(e)$ show the effect of enterotoxin on 12- and 15-d-old mice. Two distinct types of damage are apparent, either to the lamina propria or to the villus enterocytes. At $12 \mathrm{~d}$ the majority of damage is still to the lamina propria, while at $15 \mathrm{~d}$ there appear to be equivalent amounts of damage to both the lamina propria and the villus enterocytes. Fig. $1(f)$ shows enterotoxin damage at $18 \mathrm{~d}$ where there is a predominance of villus enterocyte damage. All the scanning electron micrographs presented show typical areas of damage found in all three mice at each age. Tissue damage also appears to occur in a specific sequence; that is, there are various stages of damage that may be observed on individual villi, which when viewed in series, represent a sequence of damage events (Lindsay \& Dennison, 1986).

Fig. $2(a-f)$ shows stages of enterotoxin damage observed in 15-d-old mice. The first stages (Fig. $2 a-d$ ) are observed in mice of all ages while that shown in Fig. 2(e) is restricted to early weaning mice and that in Fig. $2(f)$ to middle-late weaning mice. The initial site of enterotoxin action is the epithelium cells of the villus tip (Fig. $2 a-d$ ), after which the enterotoxin may attack the cells of the lamina propria, leaving the villus enterocytes intact (Fig. 2e), or attack the villus enterocytes, leaving the lamina propria intact (Fig. $2 f$ ). In the latter damage all the cells of the villus epithelium [enterocytes, goblet, endocrine, $\mathbf{M}$ and caveolated (tuft) cells] are desquamated (Fig. $2 f$ ).

It should be noted that no villi were observed with a basal attack pattern, that is, a ring of denuded tissue at the base of the villus indicating solely an enterotoxin attack of the crypt epithelial cells.

The enterotoxin also appears to specifically select and attack both goblet and tuft cells, in particular those cells closest to the villus tip (Fig. 3), leaving a 'hole' in the villus while the surrounding enterocytes are unaffected.

\section{DISCUSSION}

It is obvious that the enterotoxin isolated from $C$.perfringens 8-6 induces gross morphological damage to mouse ileal tissue. The type of damage and the specific sequence of events leading to the damage are similar to those observed in the rabbit (Lindsay \& Dennison, 1986). The only apparent difference is that both the goblet and tuft cells appear to be attacked in mice but not in rabbits. This selective attack is most unusual. Both cell types possess large numbers of microvilli on the cell crown, and since the microvilli are the sites of cell receptors, this suggests that only mice possess receptors for the 8-6 enterotoxin. It is possible that diet may play a role in receptor type; however, further studies are required to elucidate this.

The predominance of one particular type of villus damage at certain stages of life is unusual and requires comment. A number of external factors might produce different damage responses in animals of different ages. First, the contrasting methods of intragastric injection and oral administration. This was evaluated using 9 -d-old mice fed enterotoxin by either method and 

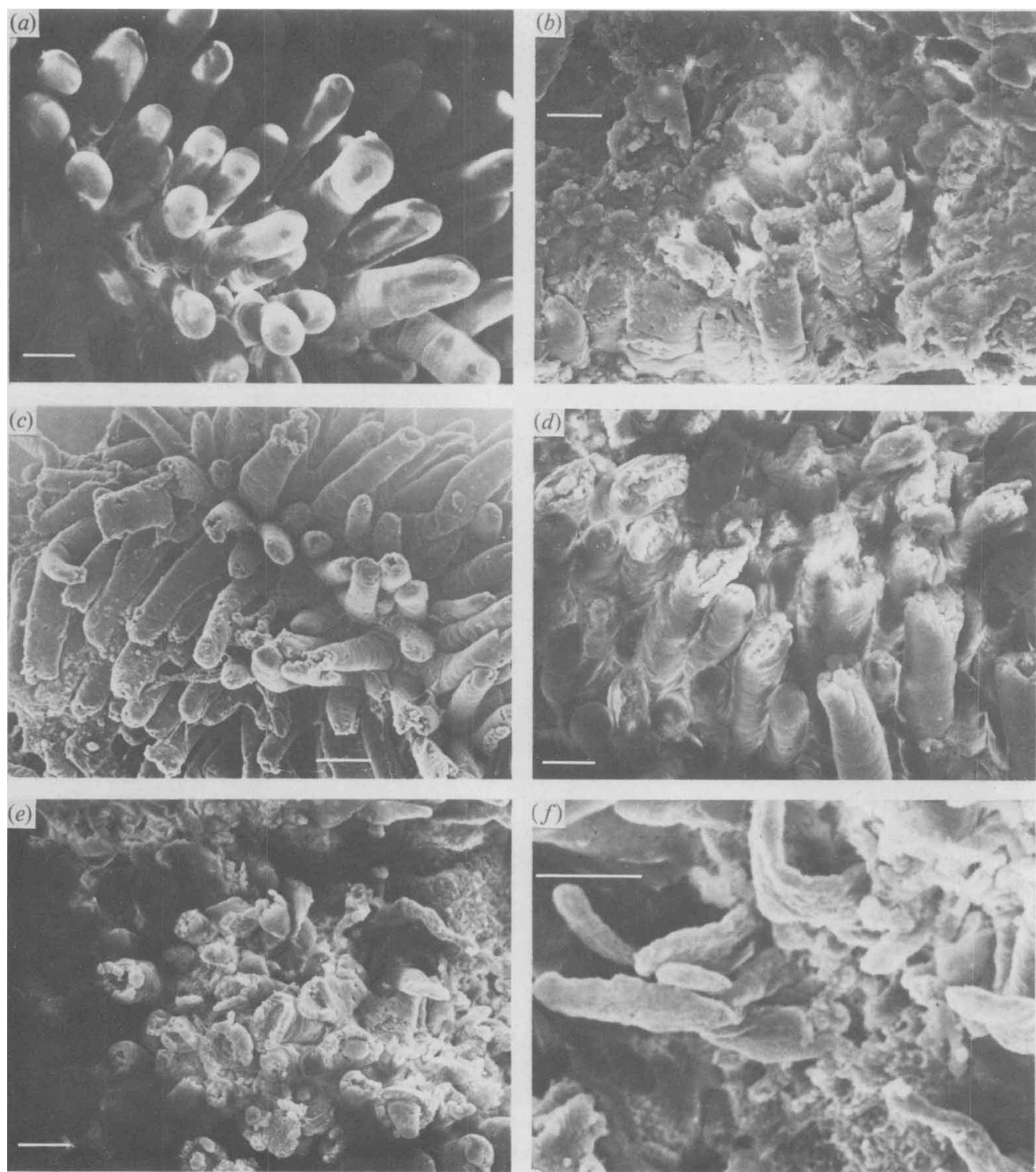

Fig. 1. Scanning electron micrographs of mouse ileal tissue. (a) Representative control (saline or untreated ileal tissue); $(b, c)$ ileal tissue from 6 - and 9-d-old mice showing desquamation of the epithelial cells of the villus tip and damage to the lamina propria; $(d, e)$ ileal tissue from $12-$ and 15 -d-old mice showing two distinct forms of damage, either to the lamina propria or to the villus enterocytes; $(f)$ ileal tissue from 18-d-old mice showing only damage to the villus enterocytes. Bars, $100 \mu \mathrm{m}$.

there appeared to be no difference in the type or amount of tissue damage resulting from either mode of administration.

Second, non-standardization of the enterotoxin dose administered on a $\mathrm{ng}$ per $\mathrm{g}$ body weight basis. Although the total average body weight of the mice in this study changed from $4 \cdot 1 \mathrm{~g}$ at $6 \mathrm{~d}$ to $9.2 \mathrm{~g}$ at $18 \mathrm{~d}$, we assumed that the actual increase in the small intestine size, and therefore weight, would be quite small. The weight of the mouse small intestine is known to change from $1.75 \%$ of total body weight (t.b.wt) at birth to $3.55 \%$ t.b.wt at $28 \mathrm{~d}$ postnatal (Altman \& Dittmer, 1964); however, the actual increase during 6-18 d postnatal is very small. Moog (1951) showed 

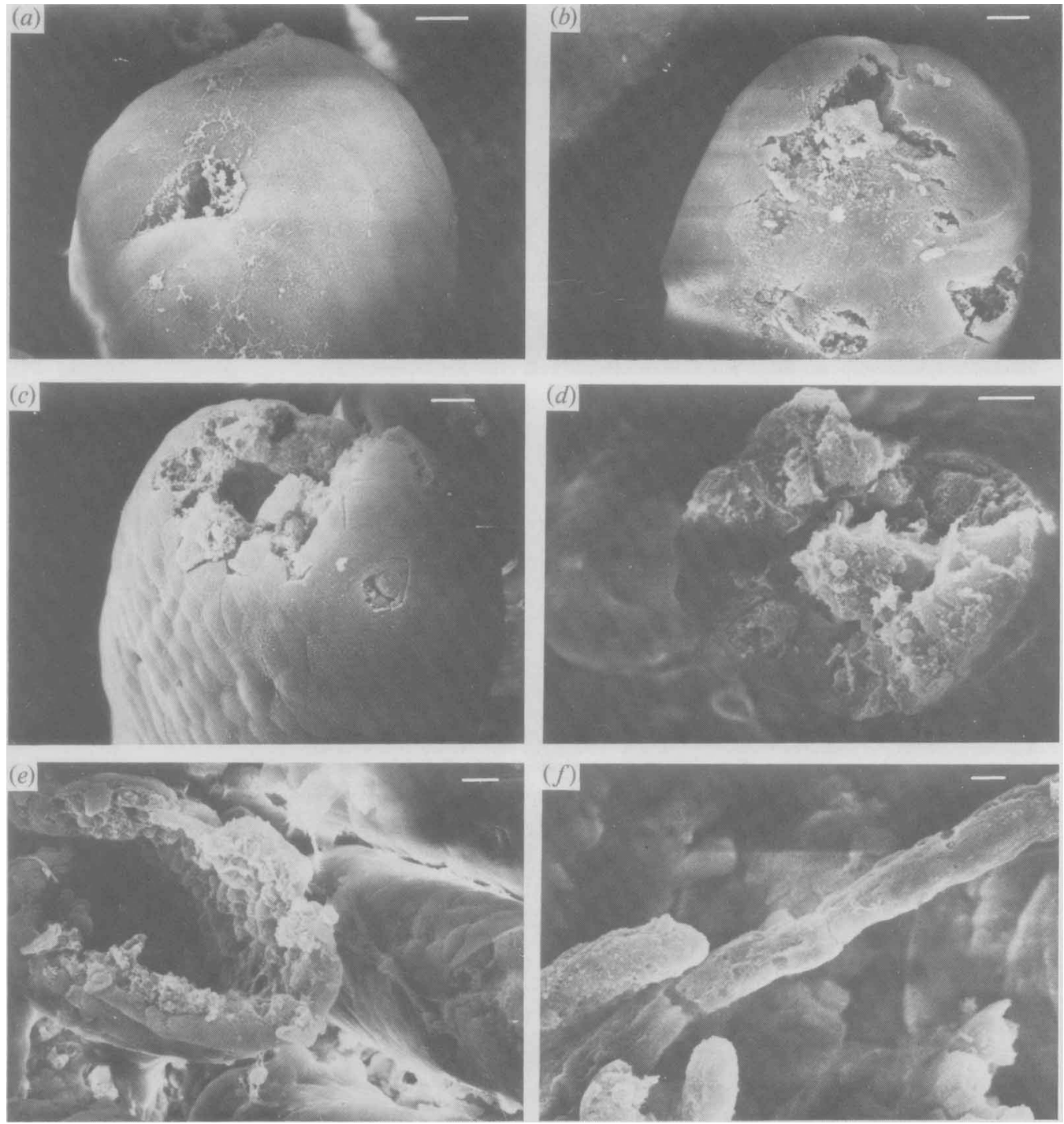

Fig. 2. Scanning electron micrographs of tissue from 15-d-old mice showing two forms of attack that an individual villus may undergo. The initial stages of villus damage are the same for mice of all ages $(a-d)$; micrographs $(e)$ and $(f)$ show the alternative types of damage related to age. $(a)$ Initial attack on villus tip epithelial cells; $(b-d)$ gradual necrosis and desquamation of villus tip epithelial cells and villus enterocytes revealing the intact lamina propria; $(e)$ villus devoid of lamina propria but with intact villus enterocytes; $(f)$ intact lamina propria devoid of villus enterocytes, goblet, endocrine, $\mathbf{M}$ and tuft cells. Bars, $10 \mu \mathrm{m}$.

that although cellular differentiation of the villi continues at an even rate during postnatal growth, the thickness of the gut wall from day 17 of gestation to $19 \mathrm{~d}$ postnatal does not change. However, the gut wall doubles in thickness between 19 and $22 \mathrm{~d}$ postnatal, which causes the observed increase in small intestine weight at $28 \mathrm{~d}$.

Third, as we were using sublethal amounts of enterotoxin, a suitable time period was required to elicit a definitive toxin/tissue response. Although the same typical patterns of damage are observed at both earlier and later incubation times in animals of different ages, $10 \mathrm{~h}$ was found to give optimal toxin/tissue response.

How can the different patterns of tissue damage then be explained? We believe that damage 

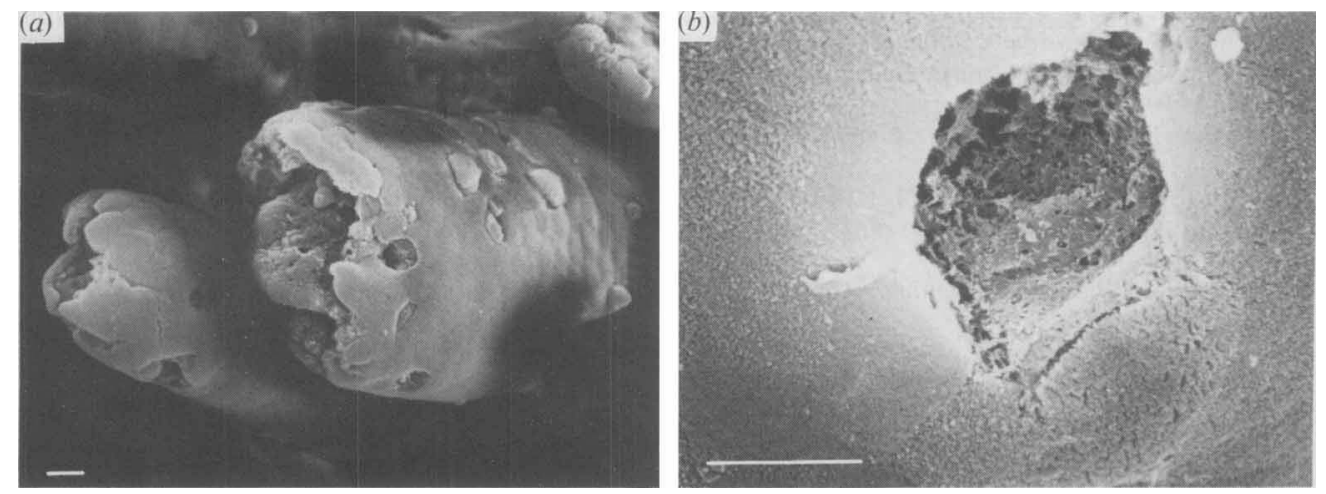

Fig. 3. Scanning electron micrographs of individual villi from 15-d-old mice after enterotoxin action. (a) Destruction of goblet and tuft cells near villus tip, leaving a 'hole' in the villus; $(b)$ at higher magnification, shows loss of a goblet cell, while the surrounding enterocytes are unaffected. Bars, $10 \mu \mathrm{m}$.

type and amount may be related to the development and immunological state of the tissue. There are two modes of absorption in the developing mammal gut, both related to age. Although in the neonate the intestinal mucosa displays a high degree of structural development (Henning \& Kretchmer, 1973) absorption of macromolecules such as proteins occurs by non-selective pinocytosis. That is, molecules are absorbed from the intestine intact, since extracellular digestion is limited. This method of absorption is also associated with the transfer of passive immunity via immunoglobulins (Henning \& Kretchmer, 1973; Ogra \& Dayton, 1979). As the mammal ages, this form of absorption decreases. Proteolytic enzymes from the stomach and pancreas and peptidases from the intestinal cells, at low levels in early suckling, rapidly increase. Extracellular digestion of macromolecules increases and active transport mechanisms in the villus enterocytes develop.

It is possible that these two different mechanisms of absorption may influence or affect toxin action in the gut. We propose that in the early neonate, intact enterotoxin is absorbed nonselectively by villus enterocytes to be deposited in the lamina propria, where it inhibits cellular functions (Lindsay \& Dennison, 1986), causing cellular destruction. The villus enterocytes will not be affected since there is no mechanism for reverse transfer of enterotoxin from the lamina propria. As the neonate ages, neonatal villus enterocytes are replaced by mature enterocytes which have been developing in the crypts. These highly active cells are now susceptible to attack since enterotoxin is not transported to the lamina propria but is digested within the enterocyte itself. Hence one would expect a changing pattern of damage with age. There is some evidence to support this proposal since it is known that younger mammals absorb more antigenic protein, which is transported to the lamina propria alone or to the lamina propria and systemic circulation, than do adult mammals (Jones, 1972; Walker \& Isselbacher, 1974; Schiller \& Walden, 1979). The implications of this proposal may be far-reaching with respect to other agerelated diseases involving bacterial toxins, for example, infant botulism (Arnon et al., 1978; Arnon, 1980; Sugiyama \& Mills, 1978; Moberg \& Sugiyama, 1979, 1980; Murrell et al., 1981).

Confirmation of many age-related toxin-induced diseases is hampered by the problem of quantification of toxin levels in individual tissues (Bonventre, 1979). If some toxins cause histopathological damage to the gut, this may be a more reliable method for characterization of infection. Further, examination of tissue damage will aid in determining how the toxin invades and is transported within the host, and the subsequent mechanisms of cell death.

\section{REFERENCES}

Altman, P. L. \& DitTMER, D. S. (1964). Biology Data Book. Washington, DC: Federation of American Societies for Experimental Biology.
ARNON, S. S. (1980). Infant botulism. Annual Review of Medicine 31, 541-560.

arnon, S. S., Damus, K., Midura, T. F., Wood, R. M. 
\& CHIN, J. (1978). Intestinal infection and toxin production by Clostridium botulinum as one cause of sudden infant death syndrome. Lancet 1, 1273-1277.

BONVENTRE, P. F. (1979). Absorption of bacterial toxin from the gastrointestinal tract. Review of Infectious Diseases 1, 663-667.

Henning, S. J. \& Kretchmer, N. (1973). Development of intestinal function in mammals. Enzyme 15, $3-23$.

JoHnSON, L. R. (1981). Physiology of the Gastrointestinal Tract. New York: Raven Press.

JONES, R. E. (1972). Intestinal absorption and gastrointestinal digestion of protein in the young rat during normal and cortisone induced closure period. Biochimica et biophysica acta 274, 412-419.

Lindsay, J. A. \& Dennison, J. D. (1986). Histopathological effect of Clostridium perfringens 8-6 enterotoxin on rabbit intestine. Current Microbiology 13, 61-66.

Lindsay, J. A., Sleigh, R. W., Ghitgas, C. \& DAVENPORT, J. B. (1985). Purification and properties of an enterotoxin from a coatless spore mutant of Clostridium perfringens type A. European Journal of Biochemistry 149, 287-293.

MCDONEL, J. L. (1980). Clostridium perfringens toxins (type A, B, C, D, E). Pharmacology and Therapeutics 10, 617-655.
Mogberg, L. T. \& Sugiyama, H. (1979). Microbial ecological basis of infant botulism studied with germ free mice. Infection and Immunity 25, 653-657.

Mogberg, L. T. \& SugiYama, H. (1980). The rat as an animal model for infant botulism. Infection and Immunity 29, 819-821.

Moog, F. (1951). The functional differentiation of the small intestine. Journal of Experimental Zoology 118, 187-205.

Murrell, W. G., Ouvrier, R. A., Stewart, B. J. \& DORMAN, D. C. (1981). Infant botulism in a breast fed infant from New South Wales. Medical Journal of Australia 1, 583-585.

OGRA, P. L. \& DAYTON, D. H. (1979). Immunology of Breast Milk. New York: Raven Press.

Schiller, C. M. \& Walden, R. (1979). Processes of transport and absorption in the developing infant intestine. Review of Infectious Diseases 1, 663-692.

SugiYama, H. \& Mills, D. C. (1978). Intraintestinal toxin in infant mice challenged intragastrically with Clostridium botulinum spores. Infection and Immunity 21, 59-63.

Walker, W. A. \& Isselbacher, K. J. (1974). Uptake and transport of macromolecules by the intestine. Gastroenterology 67, 531-550. 